\title{
MODIFY POP-UP SPRINKLER TO GIVE A WETTING SQUARE SHAPE
}

\author{
Hashad* A. A; A. M. El Metwally**; A. A. Derbala $^{* * *}$; \\ E. E. wasif**** and T. Z. Fouda ${ }^{* * *}$
}

\begin{abstract}
\end{abstract}
In order to be able to irrigate all of square area, a preliminary experiment was carried out to study the effect of changing the area crosssection of the water outlet of pop-up sprinkler on pressure and wetted radius. The pre- experiment results were used in the design and manufacture of two models, each of them consists of two parts from artilon materials, which were added to the pop-up sprinkler. A final experiment was carried out to evaluate the performance of the modified pop-up sprinkler (MPS) after adding the two parts to the sprinkler in comparison of the normal pop-up sprinkler (NPS) at the same wetted radius. The parameters under study were two designs of the fixed part \{the first design with dimensions of nozzles $(2 \times d) \mathrm{mm}$ where $d=(1.2: 8.1)$ $\mathrm{mm}$, the second design with dimensions of nozzles $(3 \times d) \mathrm{mm}$ where $d=$ (4.1:11.8) $\mathrm{mm}$ ). The positions of pressure reduce valve were closed and open. The internal nozzles dimensions of the rotor part were $\{(3 \times 8)$, $(2 \times 8),(1 \times 8)\} \mathrm{mm}$ for first design and $\{(4 \times 11.8),(3 \times 11.8),(2 \times 11.8)\}$ $\mathrm{mm}$ for second design. The results showed that, the collected water from MPS by first and second design was found to be greater than which collected from NPS at a distance of 2 and $4 \mathrm{~m}$ from the sprinkler. On the contrary, the amount of fallen water from NPS was found to be greater than which collected form MPS at a distance of 6 to $8 \mathrm{~m}$ from the sprinkler. The amount of collected water when the valve was closed was larger than one when the valve was opened. In case of the first design, the amount of fallen water near the sprinkler was increased then decreased by increasing the distance from sprinkler. Also, the amount of water fell at the angle of $\theta=(45,135,225,315)$ was greater than the amount of fallen water at the angle of $\Theta=(0,90,180,270)$.

\footnotetext{
*Graduate student, Agric. Eng. Dep., Faculty of Agric., Tanta Univ.,

${ }^{* *}$ Asso. Prof. of Agric. Eng., Agric. Eng. Dep., Faculty of Agric., Tanta Univ.,

${ }^{* * * *}$ Prof. of Agric. Eng., Agric. Eng. Dep., Faculty of Agric., Tanta Univ.,

****Head of Res. Agric., Eng., Res. Inst., Agric., Res. Center., Dokki, Giza.
} 
In case of the second design, the amount of fallen water was increased by increasing the distance from sprinkler to reach maximum value at $4 \mathrm{~m}$, then the amount of fallen water was decreased. Also, the amount of fallen water at the angle of $\theta=(0,90,180,270)$ was greater than one which fell at the angle of $\theta=(45,135,225,315)$. MPS in the first design obtained Christiansen 's uniformity coefficient smaller than that obtained by NPS. On the contrary, MPS in the second design obtained Christiansen 's uniformity coefficient greater than which obtained by NPS. MPS in the first and the second design obtained distribution uniformity $(D U)$ smaller than which obtained by NPS. MPS with the first design gave application efficiency of low quarter smaller than which obtained by NPS. MPS with the second design gave application efficiency of low quarter greater than which obtained by NPS at the same wetted radius. The smallest results of coefficient of variation for square shape $\left(C . V_{S}\right)$ recorded $15.3 \%$ by MPS with the second design and internal nozzle dimension was $(4 \times 11.8) \mathrm{mm}$ using closed valve position.

Key words: pop-up sprinkler, pressure, nozzle cross-section area, wetted area.

\section{INTRODUCTION}

W hen operation NPS inside a square area, the water is pushed in a diagonal direction. The formation of wetting is circle and its center is the position of the sprinkler. Overlapping must be done between the wetted circles to avoid non-irrigated area of 22\%, which represents the corners of the square. Hegazi, et al. (2007) tested the effect of pressure (100 to $350 \mathrm{kPa})$ and the trajectory angles range of 60 to $30^{\circ}$ (6- positions deflector) with overlapping range from 40 to $120 \%$ in square and triangular layouts. They found that, the application rate increased by increasing the water pressure. El-Berry, et al. (2009) studied the effect of nozzle pressure (137 kPa, $172.5 \mathrm{kPa}, 207$ $\mathrm{kPa}$ and $241.5 \mathrm{kPa}$ ) and nozzle shape (square, rectangle, triangle and circle) on water distribution. They found that, by increasing pressure the coefficient of uniformity increased for all nozzle shapes. Also, they reported that the noncircular nozzles have acceptable coefficient of uniformity for all pressures. Meanwhile the circular nozzles have unacceptable coefficient of uniformity at $138,172.5 \mathrm{kPa}$ and gives 
acceptable at $207 \mathrm{kPa}$ and higher. Sancheza, et al. (2011) evaluated the agricultural impact sprinklers under different combinations of pressure, nozzle diameter and meteorological conditions. They founded that, the discharge of the evaluated sprinkler increased with nozzle diameter. Amer, et al. (2012) tested a rotating sprinkler (K- Rain 75 pop-up) under 100 to $300 \mathrm{kPa}$, nozzle \#8 with $25^{\circ}$ trajectory angle and \#3 with $11^{\circ}$ and $25^{\circ}$ trajectory angle, square and rectangular layouts at $100 \%$ and $80 \%$ overlapping. They indicated that, the throw was increased by exceeding pressure regarding to creating high jet velocity by pressure. The aim of present study was to design, manufacture and evaluate the performance of NPS with a wetting square shape.

\section{MATERIALS AND METHODS}

The experimental work was carried out to design, manufacture and evaluate the performance of pop-up sprinkler with a wetting square shape. The experiments were done at the village of Kafr Hashad, Kafr ElZayyat, Gharbia Governorate, during summer 2017. The experiment area was about $(24 * 24) \mathrm{m}$ and situated at $31^{\circ} 07^{\prime}$ longitude and $30^{\circ} 79^{\prime}$ latitude. It has an elevation of about $20 \mathrm{~m}$ above mean sea level. The characteristics of the field climate during the experiment were $17 \mathrm{~km} / \mathrm{h}$ of wind speed at direction of northwest. A sprinkler irrigation line was carried out as shown in Fig. 1 to carry out the experiments. It consists of a main line with a pipe made of aluminum material with internal diameter of one inch, non-return valve, centrifugal pump with a power of $0.5 \mathrm{hp}$ Italian manufacturing, non- return valve, the control valve, pressure gauge, pressure reduce valve and the control unit connected to the lateral line. The lateral line consists of 0.75 inch polyurethane of 11 meters in length with a composite T-link with a pressure gauge and a 0.75 inch sprinkler. A preliminary experiment was carried out to study the effect of change of the cross- section area of nozzles on the pressure, the wetted diameter, the discharge at a constant rotation rate of the pump during the period of the experiment. The numbers of nozzles used in the experiment were increased from 8 to 13 nozzles with an increase of 5 nozzles by manually expanded. Nozzles cross- section areas were measured by using digital caliber. The pressure was measured by using a pressure gages with an accuracy of 0.2 bar. Wetted diameter was 
measured using long steel measuring tape as tall as $20 \mathrm{~m}$ with an accuracy of $2 \mathrm{~mm}$. The discharge from the sprinkler was measured by using a tank with capacity of $18 \mathrm{~L}$ to collect the water within $30 \mathrm{~s}$ using a stopwatch and then calibrate the volume of water collected by the tank using a $500 \mathrm{ml}$ graduated cylinder with an accuracy of $5 \mathrm{ml}$. The distribution uniformity (DU), Christiansen's uniformity coefficient (CU) and application efficiency of low quarter (AELQ) were calculated using 48 catch cans. The catch cans were $0.12 \mathrm{~m}$ internal diameter, and it placed at a distance of $2 \mathrm{~m}$ using a rope inserted every $2 \mathrm{~m}$ in 4 diagonal lines. The volume of water falling in the catch cans was measured by using a $100 \mathrm{ml}$ graduated cylinder with an accuracy of $5 \mathrm{ml}$. To find out the optimum treatment for MPS, coefficient of variation values for square shapes $\left(\mathrm{C} . \mathrm{V}_{\mathrm{S}}\right)$ were calculated by digital planimeter. The distribution of water for the optimum treatment for MPS was measured using 79 catch cans. The catch cans were placed at a distance of $2 \mathrm{~m}$ in 19 diagonal lines for quarter of the square, where one line for 5 angles.

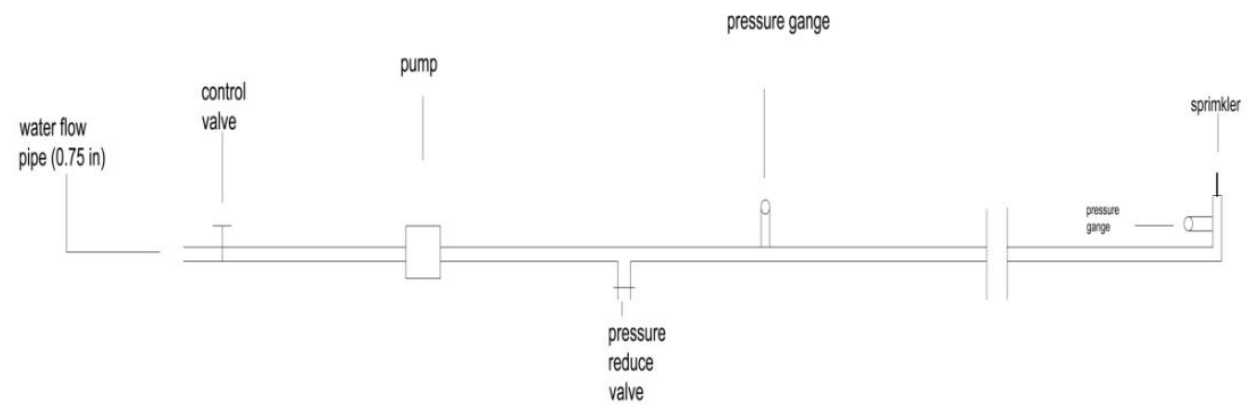

Fig. 1: Schematic diagram of sprinkler irrigation line

\section{The applied water under sprinkler irrigation}

Flow rate of sprinkler was measured at operating pressure by collecting a known volume of water in a container over a specified period (one min), and was calculated using the following Equation (Melvyn, 1983):

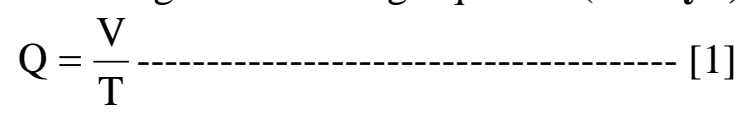

Where:

$\mathrm{Q}=$ Flow rate of sprinkler in $\mathrm{m}^{3} \mathrm{~h}^{-1}$,

$\mathrm{V}=$ Collecting water volume in $\mathrm{m}^{3}$ and

$\mathrm{T}=$ Time of collecting water in $\mathrm{h}$. 


\section{Irrigation water efficiencies}

The distribution uniformity, Christiansen's uniformity coefficient and application efficiency of low quarter were calculated for individual sprinkler. The test duration time was one and one and half hours. The collected water in catch cans was measured as a volume and divides its on cross area of catch cans to record in depth.

\section{Distribution uniformity}

The distribution uniformity (DU) was calculated by the following Equation (Heermann et al., 1990):

$$
\mathrm{DU}=\left[\frac{\mathrm{Z}_{\mathrm{lq}}}{\mathrm{Z}_{\mathrm{av}}}\right] \times 100 \text {-------------------------[ [2] }
$$

Where:

DU $=$ Distribution uniformity in \%,

$\mathrm{Z}_{\mathrm{lq}}=$ Average of catch cans depth in the low quarter in $\mathrm{mm}$ and

$\mathrm{Z}_{\mathrm{av}}=$ Average of catch cans depth in $\mathrm{mm}$.

\section{Application efficiency of low quarter}

The application efficiency of low quarter (AELQ) was calculated by the following Equation (Merriam and Keller, 1978):

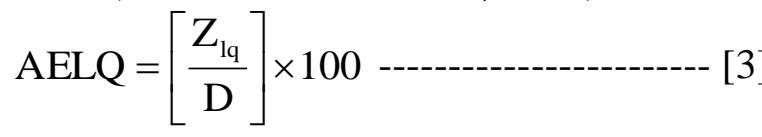

Where:
AELQ $=$ Application efficiency of low quarter in \%,
$\mathrm{Z}_{\mathrm{lq}}=$ Average of catch cans depth in the low 'quarter in $\mathrm{mm}$ and
$\mathrm{D}=$ Average depth of applied water in $\mathrm{mm}$.

\section{Christiansen's uniformity coefficient}

The Christiansen's uniformity coefficient (CU) was calculated according to the Equation of Christiansen, 1942 as follows:

$$
\mathrm{CU}=\left[1-\frac{\sum_{\mathrm{i}=1}^{N}\left|\mathrm{X}_{\mathrm{i}}-\overline{\mathrm{X}}\right|}{\mathrm{N} \overline{\mathrm{X}}}\right] \times 100
$$


Where:

$\mathrm{CU}=$ Christiansen's uniformity coefficient in \%, $\mathrm{X}_{\mathrm{i}}=$ Water depth collected by catch cans in $\mathrm{mm}$,

$\overline{\mathrm{X}}=$ Mean water depth in all catch cans in $\mathrm{mm}$ and

$\mathrm{N}=$ Total number of catch cans.

\section{Coefficient of variation for square shape}

Coefficient of variation for square shape equation was devised from Coefficient of variation equation. Where, coefficient of variation $(\mathrm{C} \mathrm{V})$ was defined as the ratio of standard deviation of the applied water depth and the average of water depth. Coefficient of variation for square shape $\left(\mathrm{C} . \mathrm{V}_{\mathrm{S}}\right)$ was calculated using the following Equation:

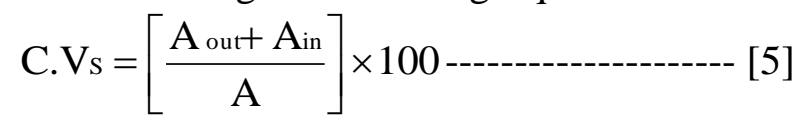

Where:

C. $V_{S}=$ Coefficient of variation for square shape in $\%$, $\mathrm{A}_{\text {out }}=$ the excess wetted area outside square shape in $\mathrm{cm}^{2}$,

$A_{\text {in }}=$ The area not wet inside square shape in $\mathrm{cm}^{2}$ and

$\mathrm{A}=$ Square area in $\mathrm{cm}^{2}$.

\section{Theoretical approach}

At the beginning of the experiment, the pressure before running the pump was recorded 2 bar. After running the pump and using the nozzle number one with the section area of $2.25 \mathrm{~mm}^{2}$, the pressure was recorded 5.8 bar, the wetted radius was $9.5 \mathrm{~m}$ at discharge of $3.6 \mathrm{~L} / \mathrm{min}$. When change the nozzle number one and installed the nozzle number 2 which a larger section area of $3.61 \mathrm{~mm}^{2}$ and operated the pump at the same speed of the previous rotation, the pressure decreased to recorded 5.6 bar, the wetted radius was increased to recorded $10 \mathrm{~m}$ and the discharge was increased to recorded $4.4 \mathrm{~L} / \mathrm{min}$. Repeat the experiment at the same speed of the pump with change cross-section area of water outlet by changing the nozzles numbers. The effect of the change in the nozzles cross-section areas on the pressure, the wetted radius and the discharge at a constant speed of the pump are listed in Table 1. The data obtained from the preexperiment were entered between the cross- section area of the nozzles (A) and the throw (L) in a straight line relationship and linked to the 
relationship between the triangle base (R), the flux (throw) (L) and the angle between them $(\Theta)$. Then, the conclusion of a relationship between

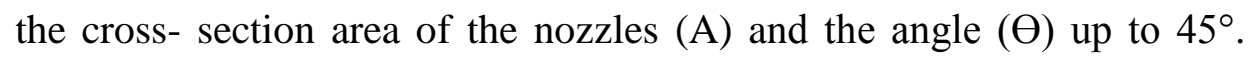
Two parts were manufactured from artilon material for two designs as shown in Figs. 2 and 3. The first part was installed in the rotor part of the sprinkler. This part contains one hole (internal nozzle) which gets out of water to the second part. The second part was installed in the fixed part of the body sprinkler. This part contains 9 holes with varying variable cross- section areas according to the equation was obtained between the cross- section area of the nozzles (A) and the angle ( $(\Theta)$ up to $45^{\circ}$. This section of second part which contains 9 holes was repeated 8 times during $360^{\circ}$ to obtain 72 holes during the whole cycle of sprinkler. This means that every $5^{\circ}$ correspond to a hole with a different cross- section area in order to obtain a square shaped pattern.

Table 1: The effect of the change in the nozzle cross-section area on the pressure, the wetted radius and the discharge at a constant of pump speed

\begin{tabular}{||c|c|c|c|c||}
\hline $\begin{array}{c}\text { Nozzle } \\
\text { number }\end{array}$ & $\begin{array}{c}\text { Cross-section } \\
\text { area, } \mathrm{mm}^{2}\end{array}$ & $\begin{array}{c}\text { Pressure, } \\
\text { bar }\end{array}$ & $\begin{array}{c}\text { Wetted } \\
\text { radius, } \mathrm{m}\end{array}$ & $\begin{array}{c}\text { Discharge, } \\
\text { L/min }\end{array}$ \\
\hline \hline 1 & 2.25 & 5.8 & 9.5 & 3.6 \\
\hline 2 & 3.61 & 5.6 & 10.0 & 4.4 \\
\hline 3 & 4.84 & 5.4 & 10.5 & 5.6 \\
\hline 4 & 6.00 & 5.2 & 11.0 & 7.6 \\
\hline 5 & 7.04 & 5.0 & 11.8 & 9.0 \\
\hline 6 & 9.75 & 4.3 & 11.8 & 11.2 \\
\hline 7 & 12.71 & 3.8 & 12.2 & 13.5 \\
\hline \hline 8 & 16.32 & 3.2 & 12.1 & 15.0 \\
\hline 9 & 18.60 & 2.8 & 11.4 & 16.8 \\
\hline 10 & 22.40 & 2.2 & 10.8 & 18.0 \\
\hline 11 & 24.80 & 1.8 & 10.3 & 20.1 \\
\hline 12 & 30.24 & 1.6 & 9.5 & 21 \\
\hline 13 & 34.31 & 1.4 & 9.2 & 22.5 \\
\hline
\end{tabular}




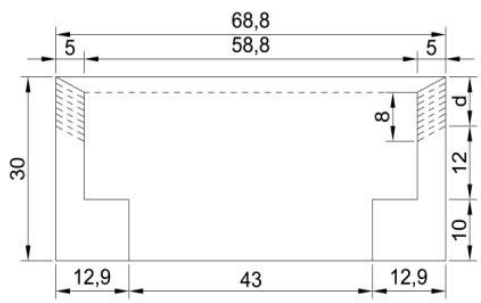

elevasion view

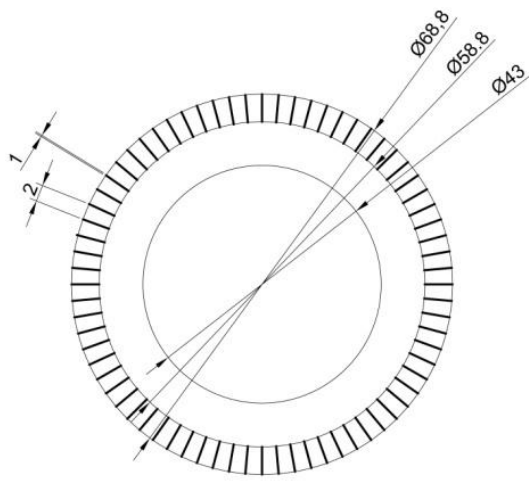

plan view

Fig. 2: Engineering drawing of first design
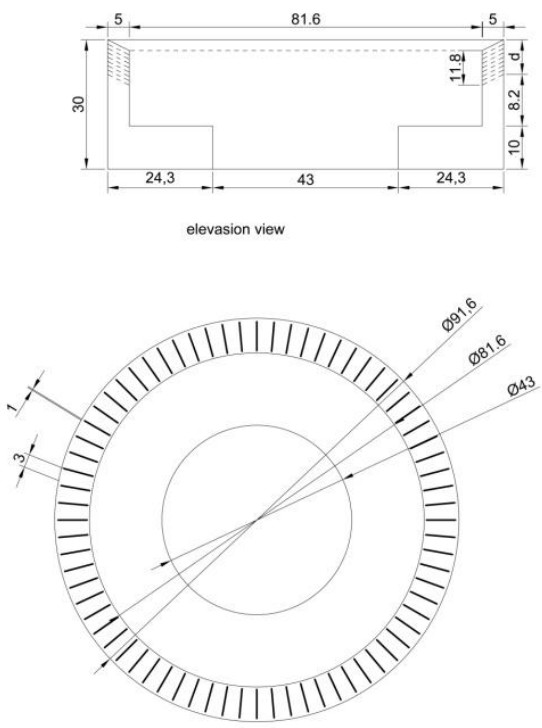

plan view

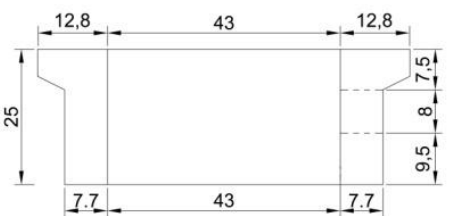

elevasion view

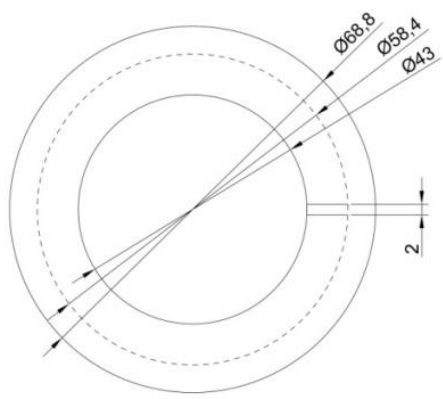

plan view

(Dim. in mm)

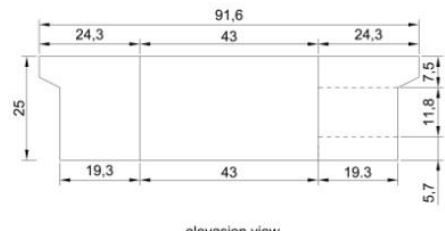

elevasion view

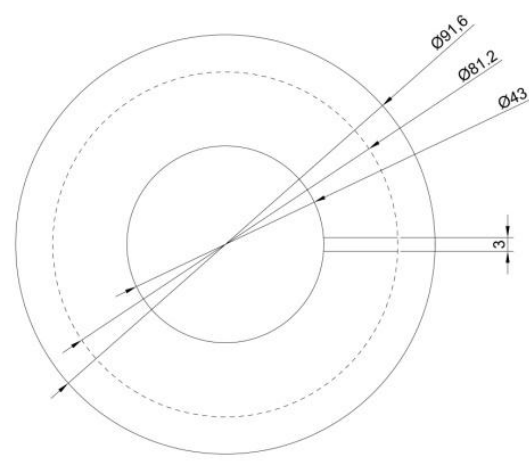

plan view

Fig. 3: Engineering drawing of second design

(Dim. in mm) 


\section{RESULTS AND DISCUSSION.}

\section{MPS with 2 positions of valve and its effect on wetted radius}

Fig. 4 shows the effect of first design sprinkler with open and closed valve on wetted radius. Wetted radius increased by about $13 \%$ from 7.5 $\mathrm{m}$ with open valve to $8.5 \mathrm{~m}$ with closed valve under the internal nozzle dimensions $(3 \times 8) \mathrm{mm}$. Meanwhile wetted radius increased by about $10 \%$ from $8.0 \mathrm{~m}$ with open valve to $8.8 \mathrm{~m}$ with closed valve under the internal nozzle dimensions $(2 \times 8) \mathrm{mm}$. The wetted radius decreased by about $7 \%$ from $7.0 \mathrm{~m}$ with open valve to $6.5 \mathrm{~m}$ with closed valve under the internal nozzle dimensions $(1 \times 8) \mathrm{mm}$. The results in Fig. 5 show the effects of second design sprinkler with open and closed valve on wetted radius. Wetted radius increased by about $17 \%$ from $6.0 \mathrm{~m}$ with open valve to 7.0 $\mathrm{m}$ with closed valve under the internal nozzle dimensions $(4 \times 11.8) \mathrm{mm}$. Also, the wetted radius increased by about $15 \%$ from $6.5 \mathrm{~m}$ with open valve to $7.5 \mathrm{~m}$ with closed valve under the internal nozzle dimensions $(3 \times 11.8) \mathrm{mm}$. Meanwhile, it increased by about $14 \%$ from $7.0 \mathrm{~m}$ with open valve to $8.0 \mathrm{~m}$ with closed valve under the internal nozzle dimensions $(2 \times 11.8) \mathrm{mm}$. From the previous results it is clear that, wetted radius recorded larger values at operated sprinkler with closed valve in comparison with operated sprinkler with open valve under all internal nozzle dimensions. Wetted radius also, increased by decreasing the internal nozzle dimensions. This is due to decrease the internal nozzle dimensions and closed the valve leads to increase the pressure and therefore increased wetted radius.

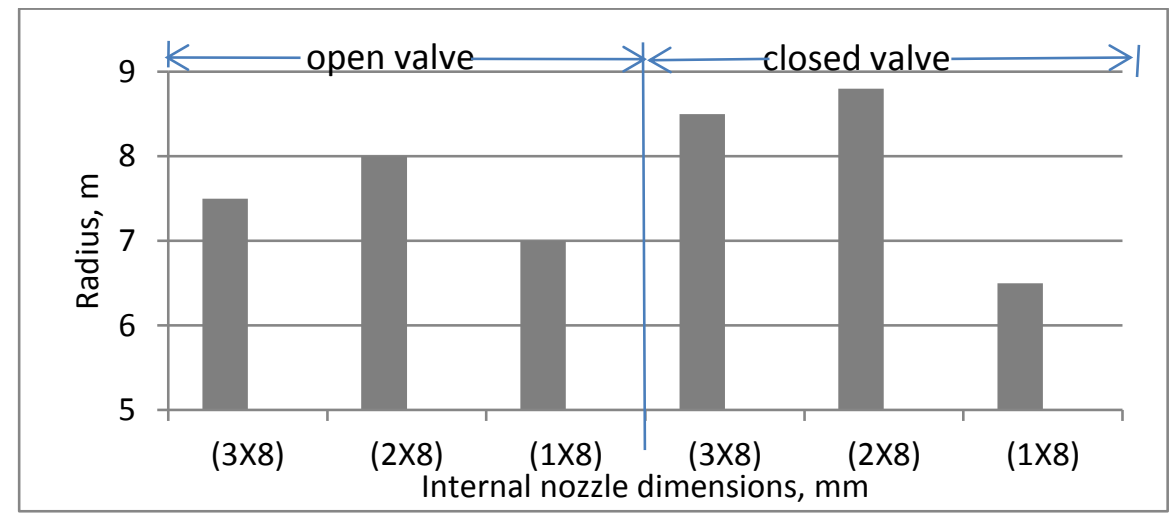

Fig. 4: Effects of the first design sprinkler on wetted radius 


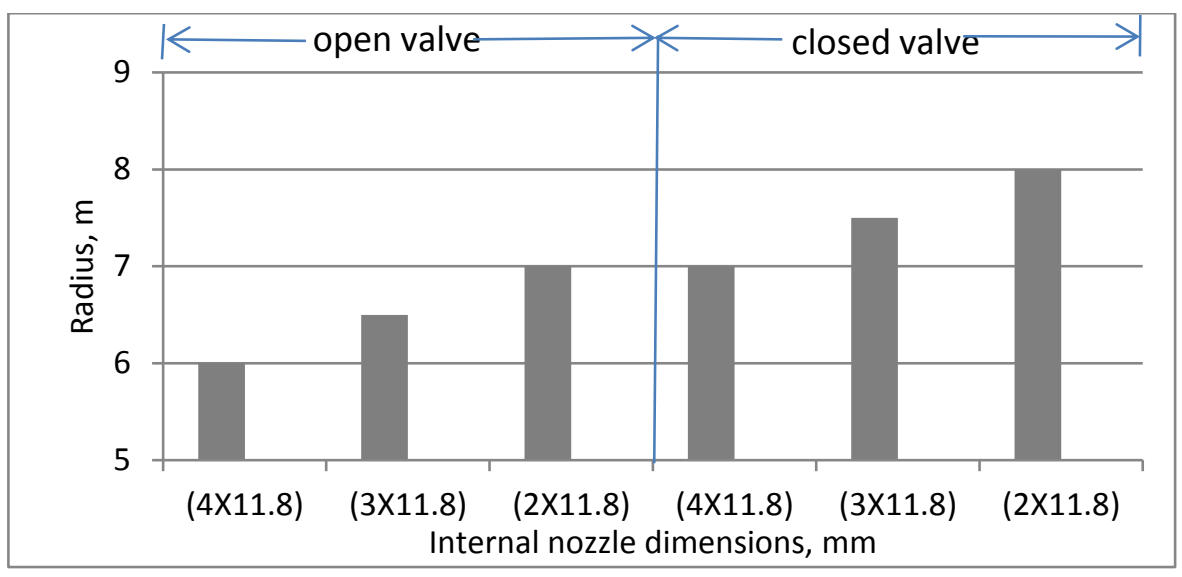

Fig. 5: Effects of the second design sprinkler on wetted radius

\section{MPS with two positions of valve and its effect on operating pressure}

Table 2 illustrates the effect of the first design sprinkler with open and closed valve on operating pressure in comparison with NPS by nozzle number of (6) at the same wetted radius. Pressure increased (under $7.5 \mathrm{~m}$ wetted radius) from 0.8 bar by NPS to (2.6:1.6) bar by MPS with internal nozzle dimensions $(3 \times 8) \mathrm{mm}$ and open valve. Pressure increased (under $8.5 \mathrm{~m}$ wetted radius) from 1.0 bar by NPS to (3.0:2.0) bar by MPS with internal nozzle dimensions $(3 \times 8) \mathrm{mm}$ and closed valve. Pressure increased (under $8.0 \mathrm{~m}$ wetted radius) from 0.9 bar by NPS to (3.6:2.6) bar by MPS with internal nozzle dimensions $(2 \times 8) \mathrm{mm}$ and open valve. Pressure increased (under $8.8 \mathrm{~m}$ wetted radius) from 1.2 bar by NPS to (4.0:3.0) bar by MPS with internal nozzle dimensions $(2 \times 8) \mathrm{mm}$ and closed valve. Pressure increased (under $7.0 \mathrm{~m}$ wetted radius) from $0.7 \mathrm{bar}$ by NPS to (4.0:3.4) bar by MPS with internal nozzle dimensions $(1 \times 8)$ $\mathrm{mm}$ and open valve. Pressure increased (under $6.5 \mathrm{~m}$ wetted radius) from 0.6 bar by NPS to (4.4:3.6) bar by MPS with internal nozzle dimensions $(1 \times 8) \mathrm{mm}$ and closed valve. Data presented in Table 3 illustrate the effect of operated the second design sprinkler with open and closed valve on operating pressure in comparison with NPS by nozzle number of (9) at the same wetted radius. Pressure increased (under $6.0 \mathrm{~m}$ wetted radius) from 0.5 bar by NPS to (0.8:1.6) bar by MPS with internal nozzle dimensions $(4 \times 11.8) \mathrm{mm}$ and open valve. Pressure increased (under 7.0 $\mathrm{m}$ wetted radius) from 0.8 bar by NPS to (1.2:2.0) bar by MPS with 
internal nozzle dimension was $(4 \times 11.8) \mathrm{mm}$ and closed valve. Pressure increased (under $6.5 \mathrm{~m}$ wetted radius) from 0.7 bar by NPS to (1.2:2.2) bar by MPS with internal nozzle dimensions $(3 \times 11.8) \mathrm{mm}$ and open valve. Pressure increased (under $7.5 \mathrm{~m}$ wetted radius) from 0.9 bar by NPS to (1.6:2.8) bar by MPS with internal nozzle dimensions $(3 \times 11.8)$ $\mathrm{mm}$ and closed valve. Pressure increased (under $7.0 \mathrm{~m}$ wetted radius) from 0.8 bar by NPS to (1.8:2.4) bar by MPS with internal nozzle dimensions $(2 \times 11.8) \mathrm{mm}$ and open valve. Pressure increased (under 8.0 $\mathrm{m}$ wetted radius) from 1.0 bar by NPS to (2.2:2.8) bar by MPS with internal nozzle dimensions $(2 \times 11.8) \mathrm{mm}$ and closed valve. In general, operating pressure recorded larger values at the first design in comparison with the second design. Operating pressure recorded larger values when operated sprinkler with closed valve in comparison with operated sprinkler with open valve under all internal nozzles dimensions. Operating pressure increased by decreasing the internal nozzles dimensions. The operating pressure in case of MPS was greater than one in case of NPS at the same wetted radius.

\section{Operated MPS with open, closed valve and its effect on discharge}

Fig. 6 shows the effect of the first design sprinkler with open and closed valve on discharge in comparison with NPS by nozzle number of (6) at the same wetted radius. Discharge increased (under $7.5 \mathrm{~m}$ wetted radius) from $5.7 \mathrm{~L} / \mathrm{min}$ by NPS to $15.0 \mathrm{~L} / \mathrm{min}$ by MPS with internal nozzle dimensions $(3 \times 8) \mathrm{mm}$ and open valve. Discharge increased (under $8.5 \mathrm{~m}$ wetted radius) from $6.3 \mathrm{~L} / \mathrm{min}$ by NPS to $18.0 \mathrm{~L} / \mathrm{min}$ by MPS with internal nozzle dimensions $(3 \times 8) \mathrm{mm}$ and closed valve. Discharge increased (under $8.0 \mathrm{~m}$ wetted radius) from $6.0 \mathrm{~L} / \mathrm{min}$ by NPS to 11.4 $\mathrm{L} / \mathrm{min}$ by MPS with internal nozzle dimensions $(2 \times 8) \mathrm{mm}$ and open valve. Discharge increased (under $8.8 \mathrm{~m}$ wetted radius) from $7.2 \mathrm{~L} / \mathrm{min}$ by NPS to $13.8 \mathrm{~L} / \mathrm{min}$ by MPS with internal nozzle dimensions $(2 \times 8)$ $\mathrm{mm}$ and closed valve. Discharge increased (under $7.0 \mathrm{~m}$ wetted radius) from $5.4 \mathrm{~L} / \mathrm{min}$ by NPS to $9.0 \mathrm{~L} / \mathrm{min}$ by MPS with internal nozzle dimensions $(1 \times 8) \mathrm{mm}$ and open valve. Discharge increased (under $6.5 \mathrm{~m}$ wetted radius) from $5.1 \mathrm{~L} / \mathrm{min}$ by NPS to $9.6 \mathrm{~L} / \mathrm{min}$ by MPS with internal nozzle dimensions $(1 \times 8) \mathrm{mm}$ and closed valve. 
Table 2: Effect of the first design sprinkler on operating pressure

\begin{tabular}{|c|c|c|c|c|c|}
\hline \multirow{2}{*}{$\begin{array}{l}\text { Wetted } \\
\text { Radius, } \\
\text { m }\end{array}$} & \multicolumn{3}{|c|}{ Modify pop-up sprinkler (MPS) } & \multicolumn{2}{|c|}{$\begin{array}{l}\text { Normal pop-up } \\
\text { sprinkler (NPS) }\end{array}$} \\
\hline & $\begin{array}{c}\text { Position } \\
\text { of } \\
\text { valve }\end{array}$ & $\begin{array}{c}\text { Internal nozzle } \\
\text { dimension, } \\
\mathrm{mm}\end{array}$ & $\begin{array}{c}\text { Pressure, } \\
\text { bar }\end{array}$ & $\begin{array}{l}\text { Nozzle } \\
\text { number }\end{array}$ & $\begin{array}{c}\text { Pressure, } \\
\text { bar }\end{array}$ \\
\hline 7.5 & \multirow{3}{*}{$\begin{array}{l}\text { Open } \\
\text { valve }\end{array}$} & $(3 \times 8)$ & $2.6: 1.6$ & 6 & 0.8 \\
\hline 8.0 & & $(2 \times 8)$ & $3.6: 2.6$ & 6 & 0.9 \\
\hline 7.0 & & $(1 \times 8)$ & $4.0: 3.4$ & 6 & 0.7 \\
\hline 8.5 & \multirow{3}{*}{$\begin{array}{l}\text { Closed } \\
\text { valve }\end{array}$} & $(3 \times 8)$ & $3.0: 2.0$ & 6 & 1.0 \\
\hline 8.8 & & $(2 \times 8)$ & $4.0: 3.0$ & 6 & 1.2 \\
\hline 6.5 & & $(1 \times 8)$ & $4.4: 3.6$ & 6 & 0.6 \\
\hline
\end{tabular}

Table 3: Effect of the second design sprinkler on operating pressure

\begin{tabular}{|c|c|c|c|c|c|}
\hline \multirow{2}{*}{$\begin{array}{c}\text { Wetted } \\
\text { Radius, } \\
\text { m }\end{array}$} & \multicolumn{3}{|c|}{ Modify pop-up sprinkler (MPS) } & \multicolumn{2}{|c|}{$\begin{array}{l}\text { Normal pop-up } \\
\text { sprinkler (NPS) }\end{array}$} \\
\hline & $\begin{array}{c}\text { Position } \\
\text { of } \\
\text { valve }\end{array}$ & $\begin{array}{c}\text { Internal nozzle } \\
\text { dimension, } \\
\text { mm }\end{array}$ & $\begin{array}{c}\text { Pressure, } \\
\text { bar }\end{array}$ & $\begin{array}{l}\text { Nozzle } \\
\text { number }\end{array}$ & $\begin{array}{c}\text { Pressure, } \\
\text { bar }\end{array}$ \\
\hline 6.0 & \multirow{3}{*}{$\begin{array}{l}\text { Open } \\
\text { valve }\end{array}$} & $(4 \times 11.8)$ & $0.8: 1.6$ & 9 & 0.5 \\
\hline 6.5 & & $(3 \times 11.8)$ & $1.2: 2.2$ & 9 & 0.7 \\
\hline 7.0 & & $(2 \times 11.8)$ & $1.8: 2.4$ & 9 & 0.8 \\
\hline 7.0 & \multirow{3}{*}{$\begin{array}{l}\text { Closed } \\
\text { valve }\end{array}$} & $(4 \times 11.8)$ & $1.2: 2.0$ & 9 & 0.8 \\
\hline 7.5 & & $(3 \times 11.8)$ & $1.6: 2.8$ & 9 & 0.9 \\
\hline 8.0 & & $(2 \times 11.8)$ & $2.2: 2.8$ & 9 & 1.0 \\
\hline
\end{tabular}

The results in Fig. 7 show the effect of the second design sprinkler with open and closed valve on discharge in comparison with NPS by nozzle number of (9) at the same wetted radius. Discharge increased (under 6.0 $\mathrm{m}$ wetted radius) from $8.1 \mathrm{~L} / \mathrm{min}$ by NPS to $18.0 \mathrm{~L} / \mathrm{min}$ by MPS with internal nozzle dimensions $(4 \times 11.8) \mathrm{mm}$ and open valve. Discharge increased (under $7.0 \mathrm{~m}$ wetted radius) from $9.6 \mathrm{~L} / \mathrm{min}$ by NPS to 21.0 $\mathrm{L} / \mathrm{min}$ by MPS with internal nozzle dimensions $(4 \times 11.8) \mathrm{mm}$ and closed valve. Discharge increased (under $6.5 \mathrm{~m}$ wetted radius) from $9.0 \mathrm{~L} / \mathrm{min}$ 
by NPS to $15.6 \mathrm{~L} / \mathrm{min}$ by MPS with internal nozzle dimensions $(3 \times 11.8)$ $\mathrm{mm}$ and open valve. Discharge increased (under $7.5 \mathrm{~m}$ wetted radius) from $10.8 \mathrm{~L} / \mathrm{min}$ by NPS to $20.4 \mathrm{~L} / \mathrm{min}$ by MPS with internal nozzle dimensions $(3 \times 11.8) \mathrm{mm}$ and closed valve. Discharge increased (under $7.0 \mathrm{~m}$ wetted radius) from $9.6 \mathrm{~L} / \mathrm{min}$ by NPS to $13.8 \mathrm{~L} / \mathrm{min}$ by MPS with internal nozzle dimensions $(2 \times 11.8) \mathrm{mm}$ and open valve. Discharge increased (under $8.0 \mathrm{~m}$ wetted radius) from $11.4 \mathrm{~L} / \mathrm{min}$ by NPS to 15.6 L/min by MPS with internal nozzle dimensions $(2 \times 11.8) \mathrm{mm}$ and closed valve. In general, discharge recorded smaller values at the first design in comparison with the second design. Discharge recorded larger values when operated sprinkler with closed valve in comparison with operated sprinkler with open valve under all internal nozzles dimensions. Discharge increased by increasing the internal nozzle dimensions. MPS gave discharge greater than which obtained by NPS at the same wetted radius.

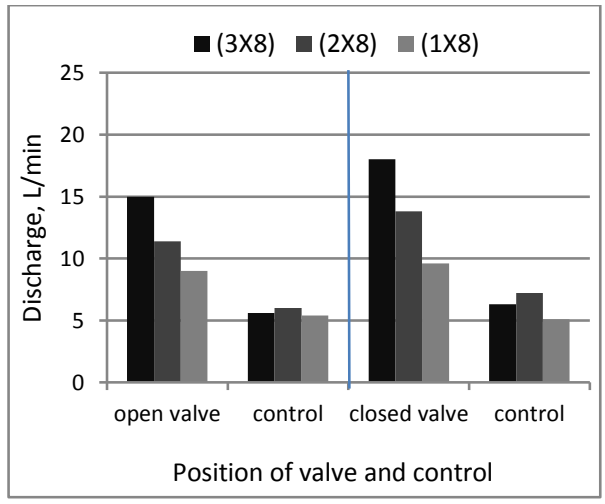

Fig. 6: Effect of the first design sprinkler on discharge

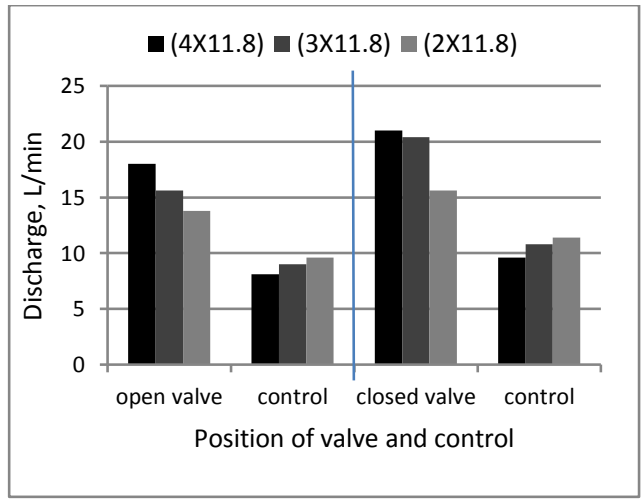

Fig. 7: Effect of the second design sprinkler on discharge

\section{Effect of MPS on Christiansen's uniformity coefficient}

Fig. 8 shows the effect of the first design sprinkler with open and closed valve on Christiansen 's uniformity coefficient (CU) in comparison with NPS by nozzle number of (6) at the same wetted radius. CU increased (under $7.5 \mathrm{~m}$ wetted radius) from $37.32 \%$ by NPS to $56.48 \%$ by MPS with internal nozzle dimensions $(3 \times 8) \mathrm{mm}$ and open valve. CU decreased (under $8.5 \mathrm{~m}$ wetted radius) from $64.25 \%$ by NPS to $41.39 \%$ by MPS 
with internal nozzle dimensions $(3 \times 8) \mathrm{mm}$ and closed valve. CU increased (under $8.0 \mathrm{~m}$ wetted radius) from $38.98 \%$ by NPS to $39.15 \%$ by MPS with internal nozzle dimensions $(2 \times 8) \mathrm{mm}$ and open valve. CU decreased (under $8.8 \mathrm{~m}$ wetted radius) from $50.85 \%$ by NPS to $47.68 \%$ by MPS with internal nozzle dimensions $(2 \times 8) \mathrm{mm}$ and closed valve. CU decreased (under $7.0 \mathrm{~m}$ wetted radius) from $39.10 \%$ by NPS to $35.77 \%$ by MPS with internal nozzle dimensions $(1 \times 8) \mathrm{mm}$ and open valve. CU decreased (under $6.5 \mathrm{~m}$ wetted radius) from $42.22 \%$ by NPS to $29.45 \%$ by MPS with internal nozzle dimensions $(1 \times 8) \mathrm{mm}$ and closed valve. The results in Fig. 9 show the effect of the second design sprinkler with open and closed valve on Christiansen 's uniformity coefficient (CU) in comparison with NPS by nozzle number of (9) at the same wetted radius. CU increased (under $6.0 \mathrm{~m}$ wetted radius) from $22.56 \%$ by NPS to $36.69 \%$ by MPS with internal nozzle dimensions $(4 \times 11.8) \mathrm{mm}$ and open valve. CU increased (under $7.0 \mathrm{~m}$ wetted radius) from $25.07 \%$ by NPS to $43.54 \%$ by MPS with internal nozzle dimensions $(4 \times 11.8) \mathrm{mm}$ and closed valve. CU increased (under $6.5 \mathrm{~m}$ wetted radius) from $20.71 \%$ by NPS to $41.49 \%$ by MPS with internal nozzle dimensions $(3 \times 11.8) \mathrm{mm}$ and open valve. $\mathrm{CU}$ decreased (under $7.5 \mathrm{~m}$ wetted radius) from $50.72 \%$ by NPS to $43.32 \%$ by MPS with internal nozzle dimensions $(3 \times 11.8) \mathrm{mm}$ and closed valve. $\mathrm{CU}$ increased (under $7.0 \mathrm{~m}$ wetted radius) from $25.07 \%$ by NPS to $44.03 \%$ by MPS with internal nozzle dimensions $(2 \times 11.8) \mathrm{mm}$ and open valve. $\mathrm{CU}$ increased (under $8.0 \mathrm{~m}$ wetted radius) from $48.62 \%$ by NPS to $52.70 \%$ by MPS with internal nozzle dimensions $(2 \times 11.8) \mathrm{mm}$ and closed valve. . In general, MPS using the first design gave CU smaller than which obtained by NPS at the same wetted radius. On the contrary, MPS using the second design gave CU greater than which obtained by NPS at the same wetted radius.

\section{Effect of MPS on distribution uniformity}

Fig. 10 illustrated that the effect of the first design sprinkler with open and closed valve on distribution uniformity (DU) in comparison with NPS by nozzle number of (6) at the same wetted radius. Distribution uniformity increased (under $7.5 \mathrm{~m}$ wetted radius) from $22.64 \%$ by NPS to $39.67 \%$ by MPS with internal nozzle dimensions $(3 \times 8) \mathrm{mm}$ and open valve. 


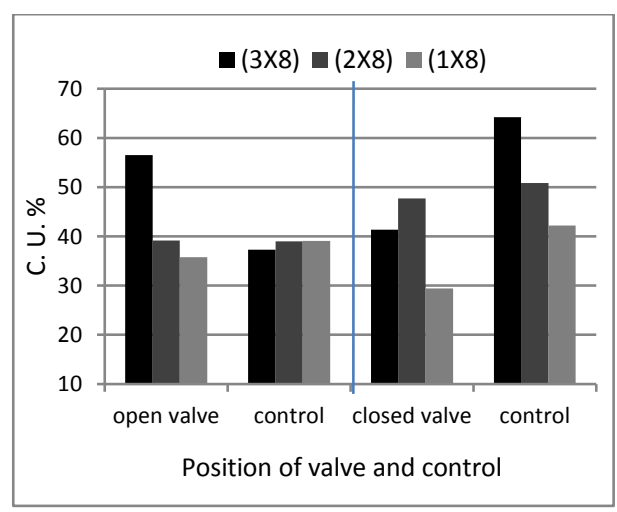

Fig. 9: Effect of the second design sprinkler on Christiansen's uniformity, CU

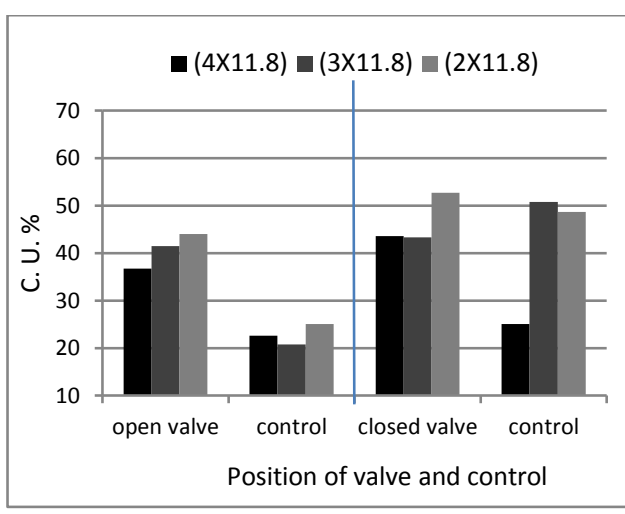

Fig. 8: Effect of the first design sprinkler on Christiansen's uniformity, CU

DU decreased (under $8.5 \mathrm{~m}$ wetted radius) from $54.24 \%$ by NPS to $32.67 \%$ by MPS with internal nozzle dimensions $(3 \times 8) \mathrm{mm}$ and closed valve. DU decreased (under $8.0 \mathrm{~m}$ wetted radius) from $31.43 \%$ by NPS to $25.37 \%$ by MPS with internal nozzle dimensions $(2 \times 8) \mathrm{mm}$ and open valve. DU decreased (under $8.8 \mathrm{~m}$ wetted radius) from $36.67 \%$ by NPS to $29.57 \%$ by MPS with internal nozzle dimensions $(2 \times 8) \mathrm{mm}$ and closed valve. DU increased (under $7.0 \mathrm{~m}$ wetted radius) from $18.32 \%$ by NPS to $20.47 \%$ by MPS with internal nozzle dimensions $(1 \times 8) \mathrm{mm}$ and open valve. DU decreased (under $6.5 \mathrm{~m}$ wetted radius) from $24.74 \%$ by NPS to $17.39 \%$ by MPS with internal nozzle dimensions $(1 \times 8) \mathrm{mm}$ and closed valve. Fig. 11 shows the effect of the second design sprinkler with open and closed valve on Distribution uniformity (DU) in comparison with NPS by nozzle number of (9) at the same wetted radius. DU increased (under $6.0 \mathrm{~m}$ wetted radius) from $24.81 \%$ by NPS to $28.37 \%$ by MPS with internal nozzle dimensions $(4 \times 11.8) \mathrm{mm}$ and open valve. DU decreased (under $7.0 \mathrm{~m}$ wetted radius) from $36.92 \%$ by NPS to $36.01 \%$ by MPS with internal nozzle dimensions $(4 \times 11.8) \mathrm{mm}$ and closed valve. DU increased (under $6.5 \mathrm{~m}$ wetted radius) from $26.82 \%$ by NPS to $32.40 \%$ by MPS with internal nozzle dimension DU $(3 \times 11.8) \mathrm{mm}$ and open valve. DU decreased (under $7.5 \mathrm{~m}$ wetted radius) from $44.44 \%$ by NPS to $28.26 \%$ by MPS with internal nozzle dimensions $(3 \times 11.8) \mathrm{mm}$ and closed valve. DU decreased (under $7.0 \mathrm{~m}$ wetted radius) from $36.92 \%$ by NPS to $21.33 \%$ by MPS with internal nozzle dimensions $(2 \times 11.8) \mathrm{mm}$ and open valve. DU decreased (under $8.0 \mathrm{~m}$ wetted radius) 
from $49.69 \%$ by NPS to $24.77 \%$ by MPS with internal nozzle dimensions $(2 \times 11.8) \mathrm{mm}$ and closed valve. In general, MPS with the first and second design gave DU smaller than which obtained by NPS at the same wetted radius.

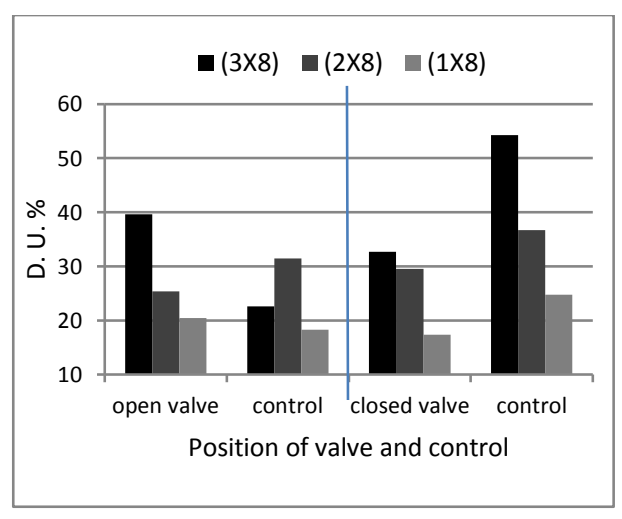

Fig. 10: Effect of the first design sprinkler on distribution uniformity, DU

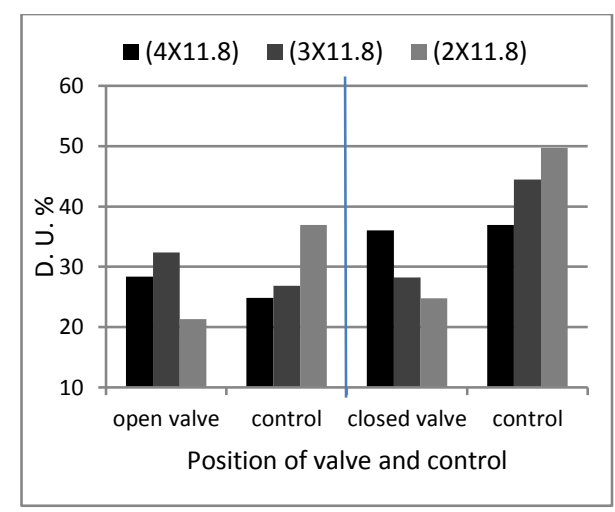

Fig. 11: Effect of the first design sprinkler on Distribution uniformity, DU

\section{Effect of MPS on application efficiency of low quarter}

Fig. 12 shows the effect of the first design sprinkler with open and closed valve on application efficiency of low quarter (AELQ) in comparison with NPS by nozzle number of (6) at the same wetted. AELQ increased (under $7.5 \mathrm{~m}$ wetted radius) from $15.26 \%$ by NPS to $33.19 \%$ by MPS with internal nozzle dimensions $(3 \times 8) \mathrm{mm}$ and open valve. AELQ decreased (under $8.5 \mathrm{~m}$ wetted radius) from $53.10 \%$ by NPS to $39.51 \%$ by MPS with internal nozzle dimensions $(3 \times 8) \mathrm{mm}$ and closed valve. AELQ decreased (under $8.0 \mathrm{~m}$ wetted radius) from $22.53 \%$ by NPS to $15.98 \%$ by MPS with internal nozzle dimensions $(2 \times 8) \mathrm{mm}$ and open valve. AELQ increased (under $8.8 \mathrm{~m}$ wetted radius) from $22.53 \%$ by NPS to $23.35 \%$ by MPS with internal nozzle dimensions $(2 \times 8) \mathrm{mm}$ and closed valve. AELQ increased (under $7.0 \mathrm{~m}$ wetted radius) from $13.83 \%$ by NPS to $14.84 \%$ by MPS with internal nozzle dimensions $(1 \times 8) \mathrm{mm}$ and open valve. AELQ decreased (under $6.5 \mathrm{~m}$ wetted radius) from $12.64 \%$ by NPS to $12.39 \%$ by MPS with internal nozzle dimensions $(1 \times 8) \mathrm{mm}$ and closed valve. Fig. 13 shows the effect of the second design sprinkler with open and closed valve on application efficiency of low quarter (AELQ) in comparison with NPS by nozzle number of (9) at 
the same wetted. AELQ increased (under $6.0 \mathrm{~m}$ wetted radius) from $13.72 \%$ by NPS to $16.86 \%$ by MPS with internal nozzle dimensions $(4 \times 11.8) \mathrm{mm}$ and open valve. AELQ increased (under $7.0 \mathrm{~m}$ wetted radius) from $23.92 \%$ by NPS to $24.20 \%$ by MPS with internal nozzle dimensions $(4 \times 11.8) \mathrm{mm}$ and closed valve. AELQ increased (under 6.5 $\mathrm{m}$ wetted radius) from $21.58 \%$ by NPS to $29.88 \%$ by MPS with internal nozzle dimensions $(3 \times 11.8) \mathrm{mm}$ and open valve. AELQ decreased (under $7.5 \mathrm{~m}$ wetted radius) from $31.89 \%$ by NPS to $23.67 \%$ by MPS with internal nozzle dimensions $(3 \times 11.8) \mathrm{mm}$ and closed valve. AELQ increased (under $7.0 \mathrm{~m}$ wetted radius) from $23.92 \%$ by NPS to $24.08 \%$ by MPS with internal nozzle dimensions $(2 \times 11.8) \mathrm{mm}$ and open valve. AELQ increased (under $8.0 \mathrm{~m}$ wetted radius) from $32.54 \%$ by NPS to $34.17 \%$ by MPS with internal nozzle dimensions $(2 \times 11.8) \mathrm{mm}$ and closed valve. In general, MPS with the first design gave AELQ smaller than which obtained by NPS at the same wetted radius. While, MPS with second design gave AELQ greater than which obtained by NPS at the same wetted radius.

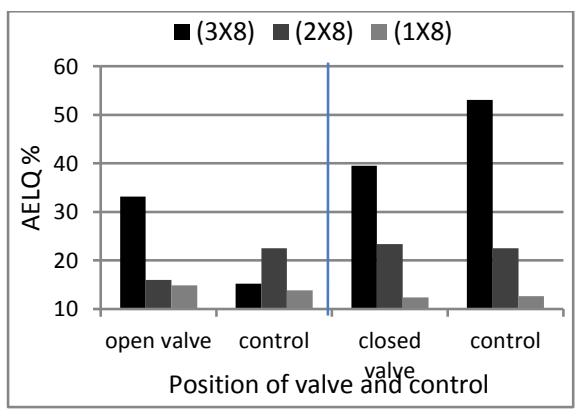

Fig. 12: Effect of the first design sprinkler on application efficiency, AELQ

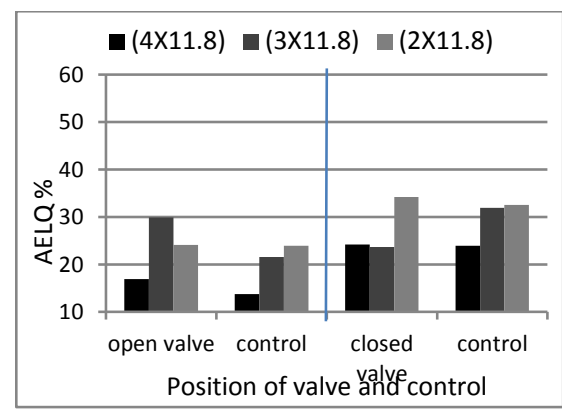

Fig.13: Effect of the second design sprinkler on application efficiency, AELQ

\section{MPS and its effect on the coefficient of variation for square shape}

Figs. from 14 to 19 indicate the wetted pattern of MPS with first design. Fig. 20 shows the effect of the first design sprinkler with open and closed valve on coefficient of variation for square shape $\left(\mathrm{C} . \mathrm{V}_{\mathrm{S}}\right)$. The maximum value of C. $\mathrm{V}_{\mathrm{S}}$. (39.7\%) was obtained by treatment of internal nozzle dimensions $(3 \times 8) \mathrm{mm}$ with open valve. While, the minimum value of C. $V_{S}$. (18.9\%) was obtained at the treatment of internal nozzle dimensions $(3 \times 8) \mathrm{mm}$ with closed valve. 


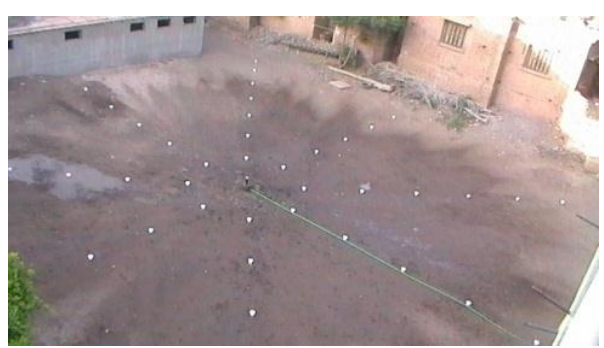

Fig. 14: The wetted pattern of MPS with first design by the internal nozzle dimensions $(3 \times 8.1) \mathrm{mm}$ and open valve

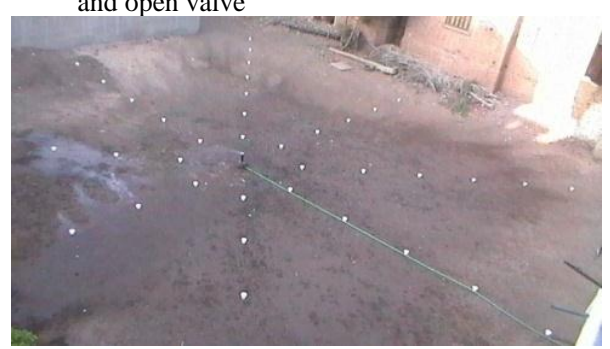

Fig. 16: The wetted pattern of MPS with first design by the internal nozzle dimensions $(2 \times 8.1) \mathrm{mm}$ and open valve

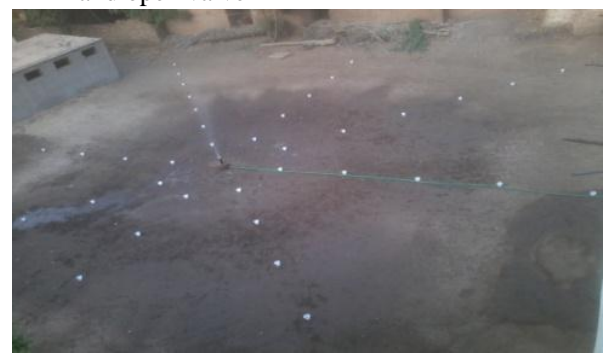

Fig. 18: The wetted pattern of MPS with first design by the internal nozzle dimensions $(1 \times 8.1) \mathrm{mm}$ and open valve

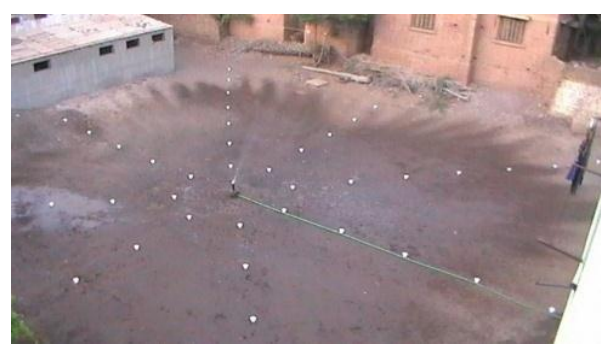

Fig. 15: The wetted pattern of MPS with first design by the internal nozzle dimensions $(3 \times 8.1) \mathrm{mm}$ and closed valve

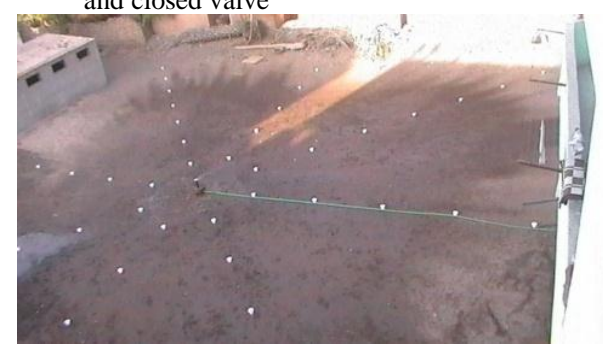

Fig. 17: The wetted pattern of MPS with first design by the internal nozzle dimensions $(2 \times 8.1) \mathrm{mm}$ and closed valve

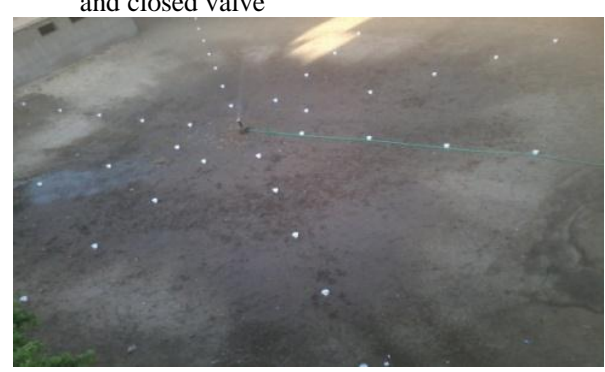

Fig. 19: The wetted pattern of MPS with first design by the internal nozzle dimensions $(1 \times 8.1) \mathrm{mm}$ and closed valve

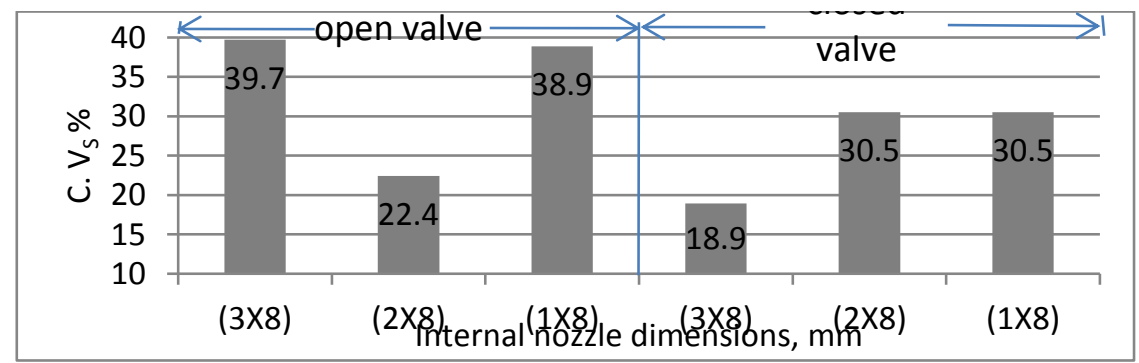

Fig. 20: Effect of the first design sprinkler with open and closed valve on the coefficient of variation for square shape, C.Vs 
Fig. from 21 to 26 indicate the wetted pattern of MPS with second design. Fig. 27 shows the effect of the second design sprinkler with open and closed valve on coefficient of variation for square shape $\left(C . V_{S}\right)$. The maximum value of $\mathrm{C} . \mathrm{V}_{\mathrm{S}}(29.7 \%)$ was obtained at the treatment of internal nozzle dimensions $(4 \times 11.8) \mathrm{mm}$ with open valve. While, the minimum value of C.V $\mathrm{V}_{\mathrm{S}}(15.3 \%)$ was obtained at the treatment of internal nozzle dimensions $(4 \times 11.8) \mathrm{mm}$ with closed valve.

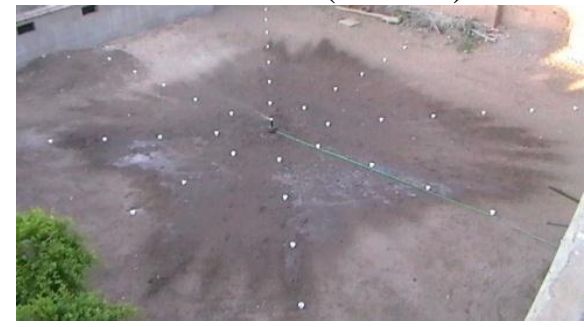

Fig. 21: The wetted pattern of MPS with second design by the internal nozzle dimensions $(4 \times 11.8) \mathrm{mm}$ and open valve

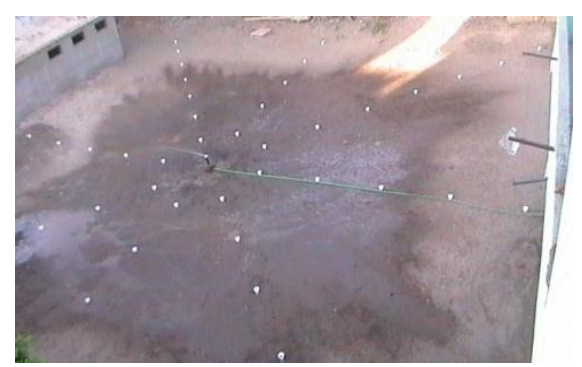

Fig. 23: The wetted pattern of MPS with second design by the internal nozzle dimensions $(3 \times 11.8) \mathrm{mm}$ and open valve

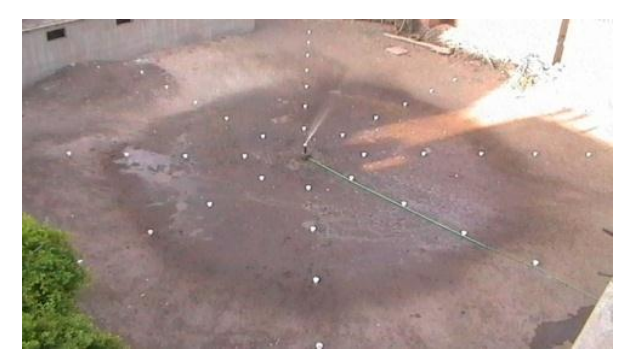

Fig. 25: The wetted pattern of MPS with second design by the internal nozzle dimensions $(2 \times 11.8) \mathrm{mm}$ and open valve

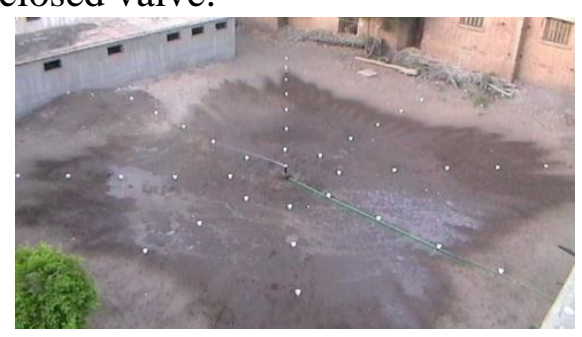

Fig. 22: The wetted pattern of MPS with second design by the internal nozzle dimensions $(4 \times 11.8) \mathrm{mm}$ and closed valve

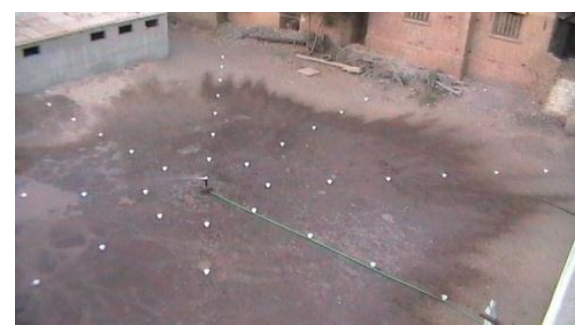

Fig. 24: The wetted pattern of MPS with second design by the internal nozzle dimensions $(3 \times 11.8) \mathrm{mm}$ and closed valve

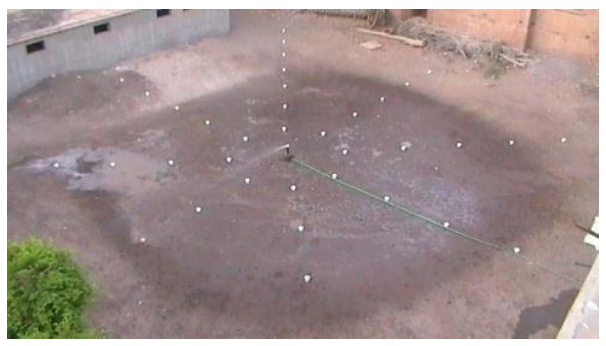

Fig. 26: The wetted pattern of MPS with second design by the internal nozzle dimensions $(2 \times 11.8) \mathrm{mm}$ and closed valve 
In general, MPS with first and second design, the treatment by the second design with internal nozzle dimensions $(4 \times 11.8) \mathrm{mm}$ using closed valve produced the smallest results of C. $\mathrm{V}_{\mathrm{S}}$.

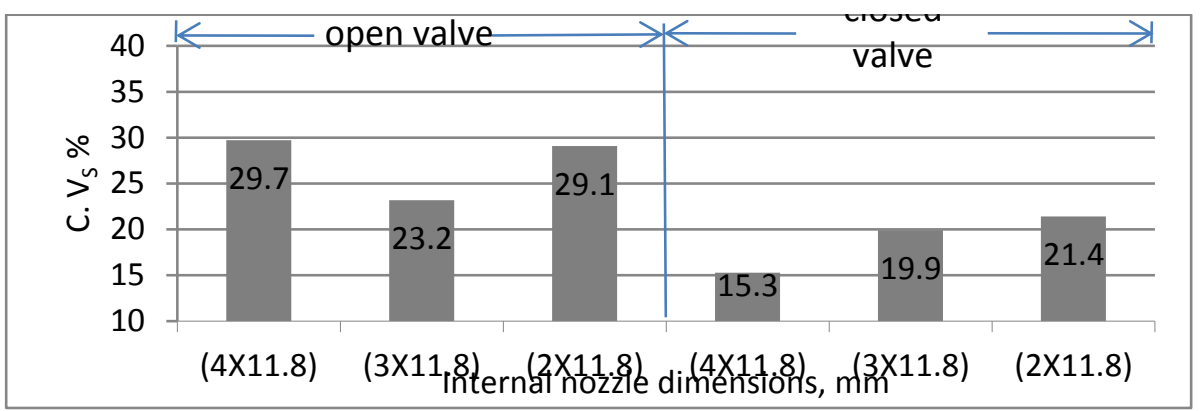

Fig. 27: Effect of the second design sprinkler with open and closed valve on the coefficient of variation for square shape, C.Vs

\section{The distribution of water for the optimum treatment for MPS compared with NPS}

The amount of water falling by MPS under the second design with $(4 \times 11.8) \mathrm{mm}$ internal nozzle dimensions and closed valve (optimum treatment) increased by increasing the distance from the sprinkler until $4 \mathrm{~m}$ and then decreased by increasing the distance from the sprinkler. This is due to the low operating pressure. The highest value of the amount of water falling at the angles $(0,90,180$ and 270) and the lowest value of the amount of water falling at the angles (45, 135, 225 and 315), because the nozzle cross-section area is the highest value at zero angle and then decreased until it reaches the lowest value at the angle of $45^{\circ}$ and then increased to reaches the highest value at the angle of 90 . This is repeated until the angle was $360^{\circ}$ degrees. While, the amount of water falling by NPS (with nozzles number (9) and 0.7 bar operating pressure) increased by increasing the distance from the sprinkler. This is due to the low operating pressure.

\section{CONCLUSIONS}

This can be obtained of wetted area with a square shaped when using the modified pop-up sprinkler (MPS) with the second design $(4 \times 11.8) \mathrm{mm}$ internal nozzle dimensions and closed valve. However, there is a decrease in the uniformity of the water distribution. Therefore, it can be recommend that we 
have to conduct more researches and experiments to increase the uniformity of water distribution by increasing the operating pressure and carry out the corresponding overlapping at low rates such as 5, 10, 15 or 20\%. Therefore, the MPS can be operated to obtain a wetted area with a square shape with acceptable water distribution ratios. Therefore, it can be reduced the number of sprinklers which used for the unit area, then the cost, the consumption water and the energy will be reduced.

\section{REFERENCES}

Amer, K. H; M. A. Aboamera; A. H. Gomaa and S. B. Deghedy (2012). Sprinkler irrigation system design and evaluation based on uniformity. Misr J. of Agric. Eng., 29 (2): 763-788.

Christiansen, J. E. (1942). Irrigation by sprinkler. California Agricultural Experiment Station. University of California. Berkeley, California, USA. Bulletin, $670.124 \mathrm{p}$.

El-Berry, A. M; M. H. Ramadan; M. A. El-Adl and H. M. Mahmoud (2009). Effect of nozzle shape and pressure on water distribution. Misr J. of Agric. Eng., 26 (1): 224-250.

Heermann, D. F; W. W. Wallender and G. M. Bos (1990). Irrigation efficiency and uniformity. (C. F. Hoffman, G. J., Howell, T. A., Solomon, K. H. (Eds.), Management of Farm Irrigation Systems. ASAE, St. Joseph, MI. 125-149).

Hegazi, M; K. H. Amer and H. M. Moghazy (2007). Sprinkler irrigation system layout based on water distribution pattern. Misr J. of Agric. Eng., 24 (2): $360-377$.

Melvyn, K. (1983). Sprinkler irrigation, equipment and practice. Bastsford Academic and Educational, London. 120 pp.

Merriam, J. L. and J. Keller (1978). Farm irrigation system evaluation. A guide for management. Logan, Utah Agricultural and Irrigation Engineering Department, Utah State University, USA. 285 pp.

Sancheza, I; J. M. Facia and N Zapatab (2011). The effects of pressure, nozzle diameter and meteorological conditions on the performance of agricultural impact sprinklers. J. of Agricultural Water Management, (102): $13-24$. 


\section{الملخص العربى \\ تعديل الرشاش القفاز ليعطي مساحة إبتلال مربعة الثكل المربق

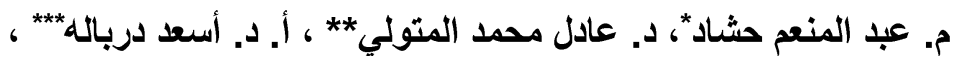

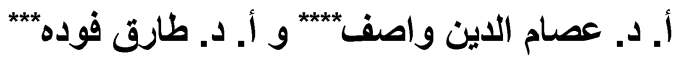

عند تشغيل رشاثـات المسطحات الخضر اء من النوع القفاز داخل مساحة مربعة الشكل يتم دفع

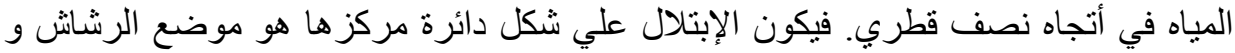

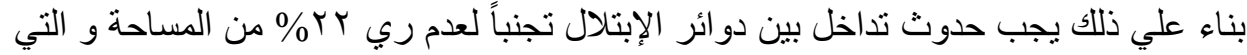

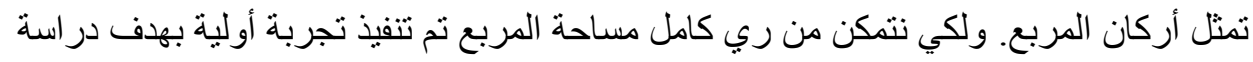

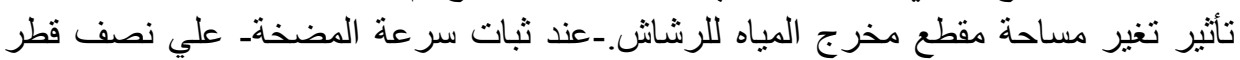

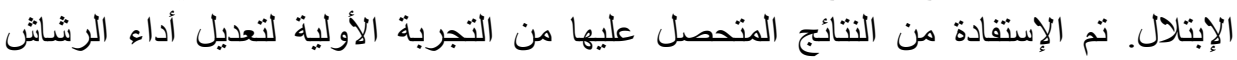
بتصميم قطعتين تضاف للرشاش. ثم تم تتفيذ تجربة نهائية بنفس موقع التجربة الأولية وفي خلال

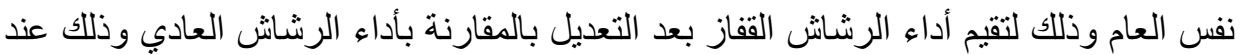

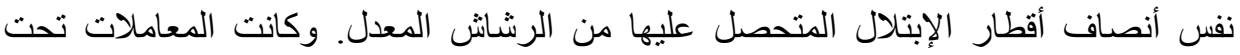

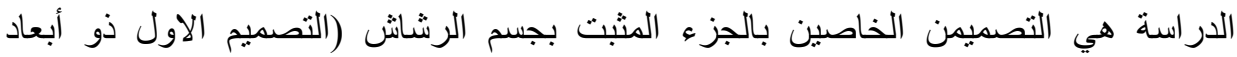

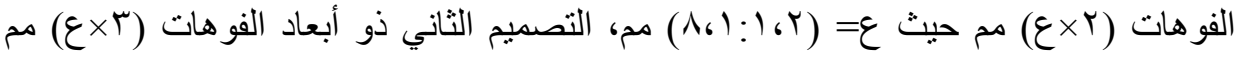

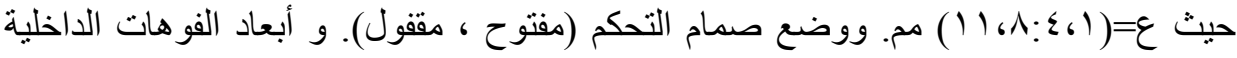

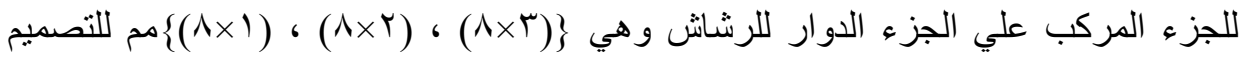

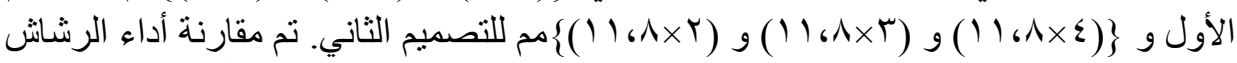

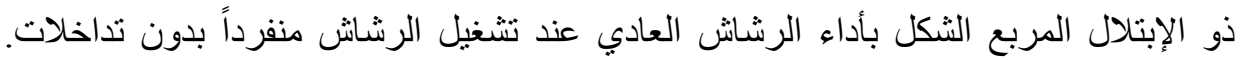

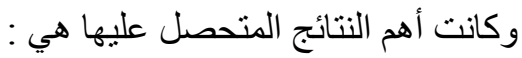
ا ـ أعطي الرشاش المعدل بالتصميم الاول قيم منخفضه لمعامل كرستيانس بالمقارنة بالرشاش العادي. و علي العكس وجد أن الرشاش المعدل بالتصميم الثاني أعطي قيم

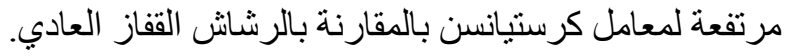

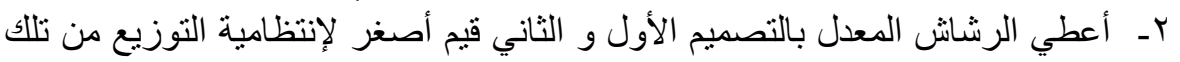
المتحصل عليها من الرشاش القفاز العادي.

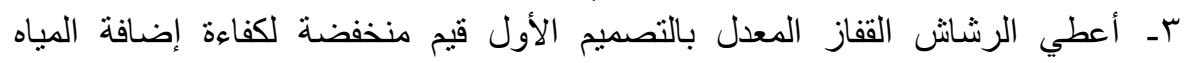

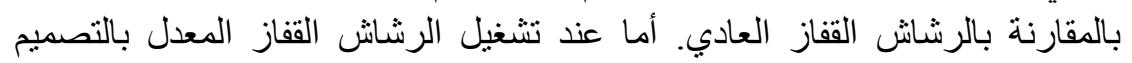
الثاني وجد أنه أعطي قيم مرتفعة لكفاءة إضافة المياه عن الرشاش الشفان القفاز العادي.

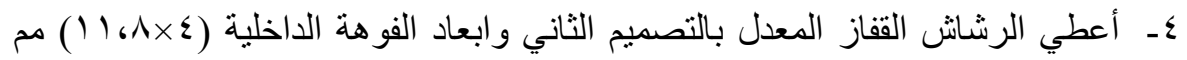

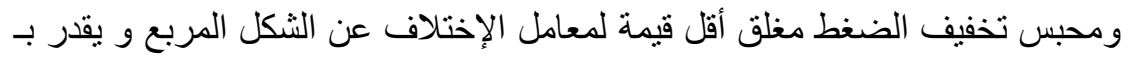

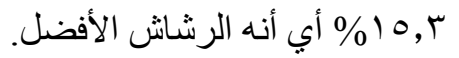

